\title{
Compression and Relaxation Properties of Municipal Solid Waste Refuse-Derived Fuel Fluff ${ }^{\dagger}$
}

\author{
Charley Sprenger, Lope G. Tabil* and Majid Soleimani \\ ${ }^{1}$ Department of Chemical and Biological Engineering, University of Saskatchewan, Canada
}

\begin{abstract}
The compression and relaxation characteristics of municipal solid waste (MSW) refuse-derived-fuel (RDF) fluff were investigated with respect to biodegradable fraction, grind size, moisture content, applied load, and pelleting temperature. Experimental trials were performed by using a single pelleting unit mounted on an Instron universal testing machine. Two grind sizes of each sample were prepared, $3.18 \mathrm{~mm}$ and $6.35 \mathrm{~mm}$, and moisture contents were increased to $8 \%, 12 \%$, and $16 \%$ w.b. The applied loads were set at $2 \mathrm{kN}, 3 \mathrm{kN}$, and $4 \mathrm{kN}$ at two temperature settings, $50{ }^{\circ} \mathrm{C}$ and $90{ }^{\circ} \mathrm{C}$. The experimental data for these trials was collected and multiple compression and relaxation models were fitted to the applied pressure, compact density or volume data. The results indicated that the compact density of RDF improved by increasing the grind size, while the compact density of biodegradable pellets increased with increasing pelleting load and temperature. The compact density of pellets produced from RDF ranged from $880-1020 \mathrm{~kg} / \mathrm{m}^{3}$; the compact density of the biodegradable pellets ranged from $1120-1290 \mathrm{~kg} / \mathrm{m}^{3}$. The Walker and Jones models both indicated that the biodegradable material fraction has a higher compressibility than the RDF material, where neither moisture content nor grind size at all levels had a significant effect on the compressibility of either material. The Kawakita-Lüdde model estimated the porosity of the pelleted samples, while the Cooper-Eaton model indicated that the primary mechanism of densification was particle rearrangement. Application of the Peleg and Moreyra model for analysis of relaxation properties of the compressed materials determined the asymptotic modulus of the residual stress to be between 89 and $117 \mathrm{MPa}$ for all experimental parameters; however, the RDF material produced more rigid pellets than the biodegradable material.
\end{abstract}

Keywords: densification, asymptotic modulus, visco-elastic properties, municipal solid waste, bio-processing, biofuels

\section{Introduction}

In an age of societal dependence on fossil-based resources, paired with concerns over environmental sustainability, researchers and policy makers are avidly looking towards biofuels as an alternative means to meet the demand for energy in future generations. In particular, 'advanced' biofuels - those that are made with materials that do not compete with food or land resourcesare of high research and development interest as a means to achieve the energy goal in the most sustainable means possible (BioFuelNet, 2015). Biofuels are recognized with being carbon-neutral, slowing the exponentially rising consequences of greenhouse gas emissions, and are developed from renewable resources.

Received 13 January 2017; Accepted 30 January 2017

J-STAGE Advance published online 31 March 2017

157 Campus Drive, Saskatoon, Saskatchewan, S7N 5A9, Canada,

* Corresponding author: Lope G. Tabil;

E-mail: lope.tabil@usask.ca

TEL: +1-306-966-5317 FAX: +1-306-966-4777
Municipal solid waste (MSW) consists of both organic and inorganic fractions and may include paper, plastic, glass, metal, food waste, wood, and other composite materials (Mor et al., 2006). There is potential for the utilization of MSW in the form of refuse derived fuel (RDF) as a feedstock for thermochemical conversion in this advanced biofuels industry. Typically, MSW is disposed of in landfills as garbage, as such the conversion to RDF would provide a more sustainable alternative disposal method for the waste. The City of Edmonton in collaboration with Enerkem Alberta Biofuels currently operates a Waste-toBiofuels facility in which processed MSW (RDF-fluff) is converted into methanol through patented, low-severity gasification technology (EWMC, 2015). Densification of this RDF-fluff would produce a higher quality feedstock that is more durable, improving storage and handling as well as providing a more uniform product for conversion.

Literature indicates that there are numerous variables that influence biomass densification; these include both process conditions and material characteristics. The process variables imposed on the densification procedure 
joelyde temperature, applied pressure, hold time, die geometry, and application rate. The addition of heat results in a reduced resistance to applied load by biomaterials (Sokhansanj et al., 2005). Increased applied pressure will indeed result in higher densities, however there is an optimal pressure that should be utilized at which the mechanical strength of the material due to plastic deformation is reached (Yaman et al., 2000). Hold times are most significant in reducing the effect of 'spring-back' from elastic deformation during compression. Die geometry influences the amount of material that can be pelleted; smaller diameters will increase the restriction and therefore the energy required to produce a pellet. Material variables such as moisture content, particle size distribution, biochemical composition, and pretreatment are characteristic of particular biomass feedstocks. Several sources indicate that moisture contents between $8-12 \%$ result in denser and higher quality pellets from cellulosic materials (Sokhansanj et al., 2005). Water acts as a binder in which the contact area of the particles is increased, allowing for the formation of bonds by van der Waal's forces (Mani et al., 2003). Particle size distribution in addition to geometric mean diameter has an effect on the quality and density of pellets (Payne, 1978). The biochemical composition of a feedstock (i.e. the fraction of starch, cellulose, protein, etc ...) will also affect the densification process and may indicate the necessity for pretreatment such as the case of lignocellulosic materials which are very resistant to deformation. Knowledge of the effects of these characteristics will assist in designing energy efficient compaction methods to produce high quality pellets for thermochemical conversion and provide understanding for the implementation of feasible waste management strategies.

Various models have been adapted in previous studies to examine the compression and relaxation characteristics of biomass feedstocks. The Jones, Walker, KawakitaLüdde, and Cooper-Eaton models are fitted to experimental compression data, while the Peleg and Moreyra model is fitted to relaxation data to determine a material's asymptotic modulus (Adapa, et al., 2010). Relationship between compression pressure and compact density, from both Walker and Jones models, indicates the compressibility of a material and points to an optimal pelleting pressure to be used for energy-efficient compaction of different samples (Mani, et al., 2006). Porosity of compacted samples estimated using the Kawakita-Lüdde model allows comparison to the solid density of the loose material; the solid density is the maximum value that can be achieved during compression where there is zero porosity. The Cooper-Eaton model hypothesizes the mechanisms of densification as particle rearrangement and deformation and that if the sum of these two parameters do not result in unity, then there must be another mechanism involved in the compaction process; thus, analysis of these parameters can assist in determining the ratio of the mechanisms involved in the densification of new materials (Adapa, et al., 2010). A material's asymptotic modulus, estimated by the Peleg and Moreyra model, implies its ability to sustain unrelaxed stresses or its rigidity (Talebi, et al., 2011). A material with a high compressibility resulting in a highly compact, rigid pellet is the desired outcome of a densification process, thus analysis of these parameters can result in optimizing the conditions for pelletization.

The objective of this study is to investigate how composition, grind size, moisture content, applied load, and processing temperature affect the compression and relaxation characteristics of MSW RDF-fluff.

\section{Materials and Methods}

\subsection{Materials}

Municipal solid waste (MSW) refuse-derived fuel (RDF) fluff was supplied by the Edmonton Waste Management Centre (EWMC), Edmonton, AB, Canada. The fluff upon receipt had a moisture content of $5.5 \%$ wet basis (w.b.) and an average bulk density of $54.6 \mathrm{~kg} / \mathrm{m}^{3}$. It is to be noted that the EWMC facility experiences RDF-fluff moisture contents of upwards of 20-30\% w.b.

Pelleting characteristics were examined for two different fractions of the RDF-fluff material. The first material utilized the RDF in its raw composition; this consisted of approximately $35 \%$ paper, $22 \%$ plastics, $14 \%$ textiles, $6 \%$ wood/organics, and the remainder fines and inerts, determined by a composition sort. The second material consisted of only biodegradable components, wood and paper, after undergoing sorting to remove plastics and textiles.

Each material was ground in two screen sizes, $3.18 \mathrm{~mm}$ and $6.35 \mathrm{~mm}$, of the knife mill (Retsch $\mathrm{GmbH}$, Haan, West-Germany). The moisture content of each of the 4 material/grind size samples was determined according to ASABE Standard S358.3 (ASABE, 2008), then adjusted to $8 \%, 12 \%$, and $16 \%$, w.b. Samples were allowed to equilibrate in air-tight containers for a minimum of 3 days prior to the start of the experiment.

\subsection{Compression and relaxation tests}

The compression tests were performed using a single pelleting unit (SPU) apparatus mounted on an Instron Universal Testing Machine (Model No. 3366, Instron Corp., Norwood, MA). This SPU consisted of a cylindrical die fixed to the base of the machine with a plunger attached to the moving crosshead of the Instron machine (Shaw, 2008). A heating element was attached to the pel- 
leting the in order to control the temperature of the procass; temperatures were compared at $50{ }^{\circ} \mathrm{C}$ and $90{ }^{\circ} \mathrm{C}$, with the pelleting protocol allowing time for the material to preheat in the die before being compressed. Approximately $0.55 \pm 0.05 \mathrm{~g}$ of biomass was fed into the die to produce each pellet. The Instron was then used to apply the load to compress the charged material at a rate of $50 \mathrm{~mm} / \mathrm{min}$ until the desired compressive force $(2,3$, and $4 \mathrm{kN}$ ) was achieved, at which point the plunger was held for $60 \mathrm{~s}$ as a retention time to avoid "spring-back" typical of densified biomass. A gate in the platform of the SPU apparatus was then opened manually to allow the plunger to eject the newly formed pellet from the die. The software programmed to control the Instron and complete the densification process recorded the time and forcedisplacement data for each pellet. Twelve pellets (replicates) were produced for each treatment combination; the dimensions and mass of each pellet was measured after each pellet was stored at room conditions for subsequent analyses.

\subsection{Data analysis}

The experimental data collected was analyzed using several compression and relaxation models for powders. All of the models were fitted to the experimental data using Microsoft Excel (Microsoft Corp., Redmond, WA) with the exception of the Cooper-Eaton model, in which SAS (Statistical Analysis System, Cary, NC) was employed. The Microsoft Excel analysis incorporated the solver tool and non-linear regression techniques, in which constants for the appropriate models were determined for each set of experimental data by the method of least squares. Acceptability of the correlation between the model constants and the experimental data was determined by the mean square error and the coefficient of determination $\left(R^{2}\right)$ of the respective models.

The purpose of fitting the compression and relaxation data of the densification experiments was to determine the relationship between compression pressure and compact density in order to determine the most energyefficient means of producing quality pellets for different material conditions.

Models proposed for analyzing the compressibility of powders have also been successfully applied to the compression of biomaterials such as timothy hay. Compression of non-metallic powders were modelled by Walker according to the volume ratio to applied pressure (Equation 1) (Walker, 1923).

$$
\frac{V}{V_{\mathrm{s}}}=m \cdot \ln P+b
$$

Where, $V=$ volume of compacted hay, $\mathrm{m}^{3} ; V_{\mathrm{s}}=$ void-free solid volume, $\mathrm{m}^{3} ; P=$ applied pressure, $\mathrm{MPa} ; m, b=\mathrm{con}$ - stants.

Jones (1960) described the compression of industrial metal powders through the linear relationship of the natural logarithm of both pressure and density (Equation 2).

$$
\ln \rho=m^{\prime} \cdot \ln P+b^{\prime}
$$

Where, $\rho=$ compact density, $\mathrm{kg} / \mathrm{m}^{3} ; m^{\prime}, b^{\prime}=$ constants.

Kawakita and Lüdde (1971) related pressure to the volume reduction of metallic powders (Equation 3).

$$
\begin{aligned}
& \frac{P}{C}=\frac{1}{a_{1} b_{1}}+\frac{P}{a_{1}} \\
& C=\frac{V_{0}-V}{V_{0}}
\end{aligned}
$$

Where, $C=$ volume ratio; $V_{0}=$ initial volume at zero pressure, $\mathrm{m}^{3} ; a_{1}, b_{1}=$ constants.

Cooper and Eaton (1962) attributed the compression of ceramic powders to two independent processes; the filling of large voids through material sliding past one another and slight fractures followed by the filling of small voids through plastic flow and fragmentation (Equation 5).

$$
\frac{V_{0}-V}{V_{0}-V_{\mathrm{s}}}=a_{2} e^{\frac{-k_{1}}{P}}+a_{3} e^{\frac{-k_{2}}{P}}
$$

Where, $a_{2}, a_{3}, k_{1}, k_{2}=$ constants.

The relaxation characteristics of solid foods are modelled by Peleg and Moreyra and can be used to compare different materials (Equation 6).

$$
\frac{F_{0} \cdot t}{F_{0}-F(t)}=k_{3}+k_{4} \cdot t
$$

Where, $F_{0}=$ initial relaxation force, $\mathrm{kN} ; F(t)=$ relaxation force at time $t, \mathrm{kN} ; t=$ time, $s ; k_{3}, k_{4}=$ constants.

A modified model by Peleg and Moreyra (1980) gives a slope index that describes the solidity of compressed materials; this can be used to determine the asymptotic modulus of solid foods and powders. The asymptotic modulus is defined as the ability of the compressed material to sustain un-relaxed stress, represented by the residual stress in the Peleg and Moreyra model (Equation 7).

$$
E_{\mathrm{A}}=\frac{F_{0}}{A_{\mathrm{a}} \varepsilon}\left(1-\frac{1}{k_{4}}\right)
$$

Where, $E_{\mathrm{A}}=$ asymptotic modulus, $\mathrm{MPa} ; \varepsilon=$ strain; $A_{\mathrm{a}}=$ cross-sectional area, $\mathrm{m}^{2}$.

The percent average relaxation was calculated by using the initial force at the beginning of the relaxation phase and the final force after an elapsed time of $60 \mathrm{~s}$ (Equation 8).

$$
\text { Percent average relaxation }=\frac{100 \times\left(F_{0}-F_{\mathrm{e}}\right)}{F_{0}}
$$

Where, $F_{\mathrm{e}}=$ final relaxation force, $\mathrm{kN}$. 


\section{Results and discussion}

The SPU trials resulted in data for 12 replicates of each material property and pelleting condition combinations. The aforementioned models were fitted to the data from these trials to evaluate the compression and relaxation characteristics for each sample. Fig. 1 displays a typical compression curve for the biodegradable material fraction of RDF.

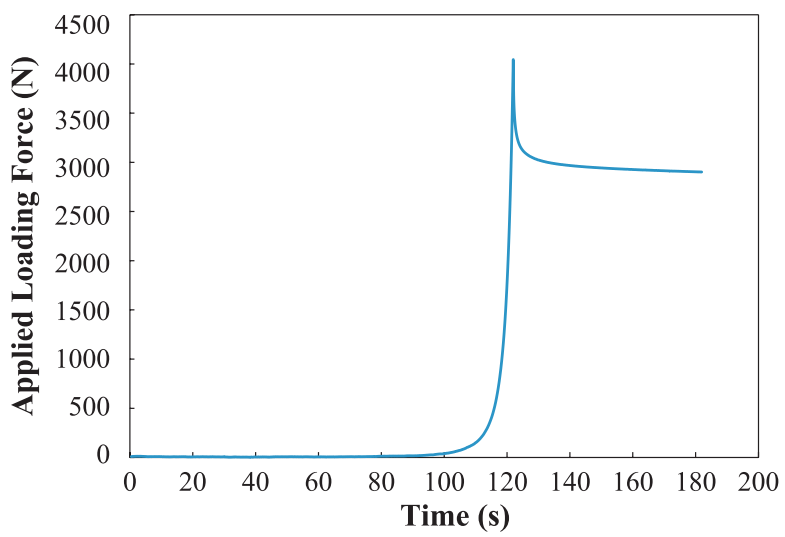

Fig. 1 Typical compression curve as a function of compression and relaxation time at preset loadings for $3.18 \mathrm{~mm}$ grind, $16 \%$ m.c. (moisture content) biodegradable material at $50{ }^{\circ} \mathrm{C}$.
The moisture content of the unprepared samples was determined to be $5.45 \%$ w.b. for the RDF material and $7.15 \%$ w.b. for the biodegradable fraction of the RDF material. These values were used to condition the samples, using the standard ASABE S358.3, to experimental moisture contents of 8,12 , and $16 \%$.

Prior to the experiments, the particle density of each material was determined for each moisture content and grind size combination using a pycnometer (Multipycnometer, Quantachrome Corp., Boynton Beach, FL); particle density is the maximum compact density that can be achieved during compression. Moisture content had little significance over the particle density; however, the densities for RDF ground by 3.18 and $6.35 \mathrm{~mm}$ screens were approximately 1350 and $1280 \mathrm{~kg} / \mathrm{m}^{3}$ (Table 1 ), respectively, while the densities for biodegradable material ground by 3.18 and $6.35 \mathrm{~mm}$ screens were approximately 1230 and $1140 \mathrm{~kg} / \mathrm{m}^{3}$, respectively.

\subsection{Density}

Table 1 shows the effects of material grind size, moisture content, pelleting load and temperature of the RDF and biodegradable materials, respectively. Densification of the RDF pellets was only affected by the material grind size, in which the material ground in a $6.35 \mathrm{~mm}$ screen in

Table 1 Effects of pelleting parameters on compact density $\left(\mathrm{kg} / \mathrm{m}^{3}\right)$ of refuse derived fuel fluff and biodegradable material fraction.

\begin{tabular}{|c|c|c|c|c|c|c|c|}
\hline \multirow{4}{*}{$\begin{array}{l}\text { Grind Size } \\
\quad(\mathrm{mm})\end{array}$} & \multirow{4}{*}{$\begin{array}{l}\text { Moisture } \\
\text { Content } \\
\text { (\% w.b.) }\end{array}$} & \multicolumn{6}{|c|}{ Applied Load (kN) } \\
\hline & & \multicolumn{2}{|c|}{2} & \multicolumn{2}{|c|}{3} & \multicolumn{2}{|c|}{4} \\
\hline & & \multicolumn{6}{|c|}{ Die Temperature $\left({ }^{\circ} \mathrm{C}\right)$} \\
\hline & & 50 & 90 & 50 & 90 & 50 & 90 \\
\hline \multicolumn{8}{|c|}{ Refuse Derived Fuel Fluff } \\
\hline \multirow{3}{*}{3.18} & 8 & $938(34)^{\mathrm{a}}$ & $885(28)$ & $887(32)$ & 887 (34) & $918(47)$ & $926(37)$ \\
\hline & 12 & $898(40)$ & $870(33)$ & $896(20)$ & $913(17)$ & $937(24)$ & $929(19)$ \\
\hline & 16 & $905(20)$ & $923(40)$ & $915(23)$ & $938(19)$ & $926(13)$ & $930(45)$ \\
\hline \multirow{3}{*}{6.35} & 8 & $950(36)$ & $972(36)$ & $993(47)$ & $1000(41)$ & $1010(29)$ & $1010(48)$ \\
\hline & 12 & $988(44)$ & $979(40)$ & 989 (49) & $998(42)$ & $1007(58)$ & $990(35)$ \\
\hline & 16 & $982(36)$ & $1014(40)$ & $991(39)$ & $1018(34)$ & $993(59)$ & $1010(28)$ \\
\hline \multicolumn{8}{|c|}{ Biodegradable material } \\
\hline \multirow{3}{*}{3.18} & 8 & $1126(15)$ & $1134(21)$ & $1194(27)$ & $1218(18)$ & $1206(28)$ & $1237(22)$ \\
\hline & 12 & $1179(19)$ & $1190(19)$ & $1199(12)$ & $1232(24)$ & $1235(22)$ & $1250(34)$ \\
\hline & 16 & $1154(15)$ & 1175 (13) & 1194 (29) & $1217(16)$ & $1219(17)$ & 1254 (29) \\
\hline \multirow{3}{*}{6.35} & 8 & $1122(15)$ & 1155 (38) & $1181(27)$ & 1199 (14) & $1253(25)$ & $1285(18)$ \\
\hline & 12 & $1135(25)$ & $1184(33)$ & 1189 (29) & 1227 (19) & $1233(23)$ & 1255 (14) \\
\hline & 16 & $1161(30)$ & $1182(20)$ & $1204(36)$ & $1217(21)$ & $1227(18)$ & $1242(21)$ \\
\hline
\end{tabular}

\footnotetext{
${ }^{\text {a }}$ Value in parentheses indicates the sample standard deviation where $n=12$.
} 
the knife mill resulted in greater compaction. Compact density of the biodegradable pellets increased with increasing pelleting load and temperature, while there was no significant effect of moisture content or grind size of the material. There were significant differences in the compact density of the two materials; the biodegradable material produced high density pellets; $1100-1250 \mathrm{~kg} / \mathrm{m}^{3}$, at all applied pressure and temperature combinations, while the RDF material produced pellets with densities of $850-1000 \mathrm{~kg} / \mathrm{m}^{3}$. Bulk density of the pellets produced during the single-pelleting trial was unable to be measured due to the small sample size, however a bulk density of pellets produced in a subsequent pilot-scale trial was determined to be approximately $590 \mathrm{~kg} / \mathrm{m}^{3}$ and $660 \mathrm{~kg} / \mathrm{m}^{3}$ for RDF and biodegradable materials, respectively. The bulk density of the raw RDF-fluff was $55 \mathrm{~kg} / \mathrm{m}^{3}$, therefore both the RDF and the sorted biodegradable materials produced a feedstock that was at least 10 times denser than the original product following pelletization.

\subsection{Compression models}

The relationship between pressure, volume, and density of the RDF and biodegradable material during the compression portion of the tests (i.e. until maximum loading was achieved) were fitted to models that have been developed for powders. The Walker model describes the relationship of volume ratio to pressure, which decreases linearly as the pressure increases. All test combinations resulted in a fitted Walker model that yielded an average coefficient of determination value $\left(R^{2}\right)$ of greater than 0.90. Fig. 2 shows a sample relationship between the volume ratio and the natural logarithm of applied pressure. The slope, $m$, of the fitted Walker model is referred to as the compressibility constant and it remained fairly constant for all parameter tests for each material type. For

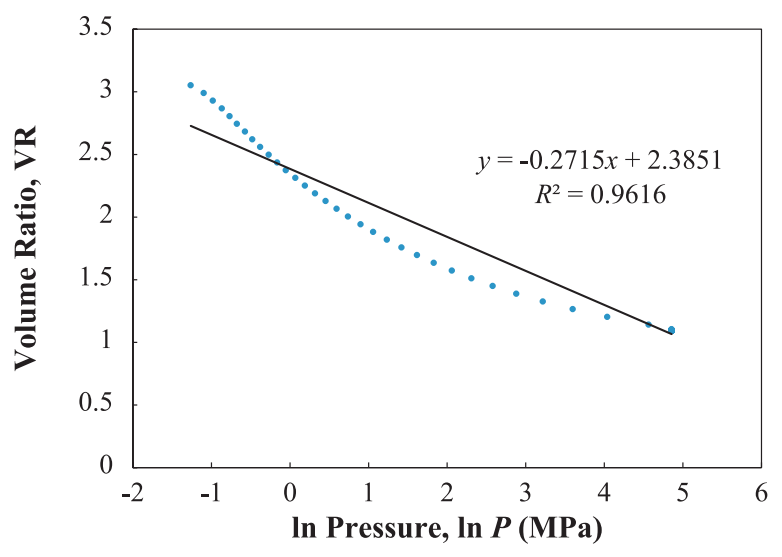

Fig. 2 Fitted Walker model relationship to compression data for $3.18 \mathrm{~mm}, 16 \%$ m.c. biodegradable material under pelleting conditions of $4 \mathrm{kN}$ applied force and $50{ }^{\circ} \mathrm{C}$ die temperature.
RDF samples, the slope had an average value of -0.3197 with a standard deviation of 0.0194; while the biodegradable fraction of RDF had an average slope value of -0.3410 with a standard deviation of 0.0235 . The biodegradable samples showed a higher slope (absolute value) indicating higher compressibility than the RDF material. This variation could probably be attributed to the different compression properties of the additional plastic fraction in the RDF material. The value of ' $b$ ' was greater at lower grind size and for the RDF material.

The Jones model describes the relationship of compact density to pressure, which increases linearly as the pressure increases. All test combinations resulted in a wellfitted Jones model, yielding an average $R^{2}$ value of greater than 0.97 . The values of the slope, $m$ ', for the model indicates the compressibility of the material. For RDF samples, the slope had an average value of 0.1644 with a standard deviation of 0.0084; while the biodegradable samples had an average slope value of 0.1906 with a standard deviation of 0.0079 . Similar to the results of the Walker model, the biodegradable samples showed a higher slope $(m$ ') indicating higher compressibility than the RDF material. For all moisture content/grind size combinations, the value of the slope appeared to decrease with an increase in either pelleting conditions, temperature or applied load. There was no significant difference in compressibility between trials with different material conditions, moisture content or grind size. The value of $b$ ' of the Jones model was relatively constant for all tests for both RDF and biodegradable materials at an average (standard deviation) of 7.2331 (0.1611) and 7.5622 (0.1509), respectively.

The Kawakita and Lüdde model indicated a good fit to the data, resulting in mean square error (MSE) values of less than $5 \times 10^{-4}$. However, there was no correlation found between the model constants and any of the experimental variables for either material. Established by Kawakita and Lüdde (1971), the model constant $a_{1}$ represents the initial porosity of the sample, while the parameter $1 / b_{1}$ indicates the yield strength or failure stress of the compaction process (MPa). As such, the model indicates a higher average initial porosity for RDF material at a grind size of $6.35 \mathrm{~mm}, 0.899$ compared to 0.753 at the $3.18 \mathrm{~mm}$ grind size. This is reasonable as the smaller particles would exhibit greater mechanical interlocking and thus, a lower initial porosity. The opposite observation is made for that of the biodegradable material, in which model determined initial porosities of 0.801 and 0.772 were for grind sizes of $3.18 \mathrm{~mm}$ and $6.35 \mathrm{~mm}$, respectively. This contradiction may be attributed to the fact that while the materials were ground using a particular screen size, not all of the particles were exactly the same size; a particle size analysis indicated that the biodegradable material, once ground, consisted of a higher fraction of fine 
partichles than the equivalent RDF ground material. Decrodse in grind size resulted in a decrease in the yield stress $\left(1 / b_{1}\right)$ for both the RDF and biodegradable material, however the actual values (standard deviation) were similar at $2.59(0.61) \mathrm{kPa}$ and $2.65(0.60) \mathrm{kPa}$, respectively.

Cooper-Eaton model speculates the two mechanisms involved in densification; particle rearrangement and deformation. The constants $a_{2}$ and $a_{3}$ in the Cooper-Eaton model, respectively represent the two mechanisms. Fitting the model to the experimental data yielded values for $a_{2}$ ranging from 0.66 to 0.97 and values for $a_{3}$ ranging from 0.00 to 0.23 ; this indicates that the majority of the compaction mechanism is resultant of particle rearrangement by the filling of large pores. The $R^{2}$ values for each sample were above 0.86 with most being at least 0.95 , indicating a good fit of the model to the experimental data.

\subsection{Relaxation characteristics}

After the desired compression pressure was reached through the applied loading, the relaxation characteristics were observed for all trials. Noticeable relaxation was observed during the $60 \mathrm{~s}$ holding period; this indicates that complete plastic deformation was not fully achieved upon the applied loading.

The Peleg and Moreyra model was fitted to the linearized data of compressive pressure in relation to relaxation time. The slope of the model, $k_{4}$, is referred to as the solidity index and was used to calculate the asymptotic modulus, $E_{\mathrm{a}}$, for the material. The asymptotic modulus indicates a material's ability to sustain unrelaxed stresses, such that a higher $E_{\mathrm{a}}$ leads to a more rigid restraint of a pellet's compact density (Table 2). Pellets produced from RDF material resulted in an asymptotic modulus of between 94 and $117 \mathrm{MPa}$, while the biodegradable pellets had an $E_{\mathrm{a}}$ value of 89 to $103 \mathrm{MPa}$. This indicates that the RDF material produces a more rigid pellet than the biodegradable material. The combined effects of pelleting tem- perature and initial moisture content have a positive correlation with the asymptotic modulus value for each material. Pellets produced at $90{ }^{\circ} \mathrm{C}$ had $E_{\text {a }}$ values 3 to 17 percent larger than those produced at $50{ }^{\circ} \mathrm{C}$; the highest percent difference was observed at $16 \%$ m.c. (w.b.) for each grind size. The asymptotic modulus values calculated for the RDF-fluff samples were comparable to other biological materials according to literature; for example corn stover, barley straw, and wheat straw display $E_{\mathrm{a}}$ values between 20 and $160 \mathrm{MPa}$ (Mani et al., 2006).

As previously noted, relaxation was observed during the experiment and was quantified as the percent average relaxation (PAR) (Table 3). Values ranging from 21 to $35 \%$ and from 29 to $37 \%$ were determined for the RDF and biodegradable pellets, respectively. These values are consistent with literature values for timothy hay, wherein PAR values of 27 to $53 \%$ were published (Talebi, et al., 2011). As with the asymptotic modulus, die temperature has the highest positive correlation to PAR.

\section{Conclusions}

The compression and relaxation characteristics of RDFfluff samples were investigated and the following conclusions were made:

1. The compact density of RDF pellets was only affected by grind size, in which it was greatest with material that was ground with a $6.35 \mathrm{~mm}$ screen in the knife mill; compact density of biodegradable pellets increased with increasing pelleting load and temperature, while there was no significant effect of moisture content or grind size of the material.

2. Both Walker and Jones model resulted in good fits to the experimental data and indicated that the biodegradable material had a higher compressibility than the RDF material for all conditions.

3. Fitting of the Kawakita-Lüdde model to the compres-

Table 2 Effects of experimental variables on asymptotic modulus, $E_{\mathrm{a}}(\mathrm{MPa})$.

\begin{tabular}{cccccc}
\hline \multirow{2}{*}{$\begin{array}{c}\text { Grind Size } \\
(\mathrm{mm})\end{array}$} & $\begin{array}{c}\text { Moisture } \\
\text { Content } \\
(\% \text { w.b. })\end{array}$ & \multicolumn{2}{c}{ Refuse Derived Fuel Fluff } & \multicolumn{2}{c}{ Biodegradable Material } \\
\cline { 3 - 5 } & 8 & $102.31(2.06)^{\mathrm{a}}$ & $105.91(0.98)$ & $96.23(0.39)$ & $99.23(12.10)$ \\
\hline \multirow{2}{*}{3.18} & 12 & $94.33(1.45)$ & $99.76(1.57)$ & $98.06(0.16)$ & $102.07(0.76)$ \\
& 16 & $100.28(9.40)$ & $117.99(3.92)$ & $91.07(0.87)$ & $95.56(0.49)$ \\
& 8 & $102.92(1.06)$ & $108.68(1.55)$ & $96.88(0.49)$ & $102.43(2.17)$ \\
6.35 & 12 & $100.24(4.68)$ & $104.10(1.58)$ & $93.82(1.91)$ & $99.88(1.94)$ \\
& 16 & $102.26(8.68)$ & $116.65(2.04)$ & $89.11(3.56)$ & $98.45(3.89)$ \\
\hline
\end{tabular}

\footnotetext{
${ }^{\text {a }}$ Value in parentheses indicates the sample standard deviation where $n=6$.
} 
Table 3 Effects of experimental variables on percent average relaxation, PAR (\%).

\begin{tabular}{|c|c|c|c|c|c|}
\hline \multirow{3}{*}{$\begin{array}{l}\text { Grind Size } \\
\quad(\mathrm{mm})\end{array}$} & \multirow{3}{*}{$\begin{array}{l}\text { Moisture } \\
\text { Content } \\
\text { (\% w.b.) }\end{array}$} & \multicolumn{2}{|c|}{ Refuse Derived Fuel Fluff } & \multicolumn{2}{|c|}{ Biodegradable Material } \\
\hline & & \multicolumn{4}{|c|}{ Die Temperature $\left({ }^{\circ} \mathrm{C}\right)$} \\
\hline & & 50 & 90 & 50 & 90 \\
\hline \multirow{3}{*}{3.18} & 8 & $31.41(1.15)^{\mathrm{a}}$ & $28.00(0.52)$ & $33.47(0.28)$ & $34.58(1.16)$ \\
\hline & 12 & $35.46(0.71)$ & $31.90(1.20)$ & $32.02(0.19)$ & $29.11(0.51)$ \\
\hline & 16 & $31.86(5.15)$ & $21.65(1.18)$ & $36.52(0.71)$ & $33.40(0.39)$ \\
\hline \multirow{3}{*}{6.35} & 8 & $31.53(0.38)$ & $27.44(0.76)$ & $32.29(1.44)$ & $29.16(1.07)$ \\
\hline & 12 & $32.23(2.65)$ & $29.43(0.39)$ & $34.71(1.30)$ & $30.25(1.34)$ \\
\hline & 16 & $31.17(4.84)$ & $22.62(1.07)$ & $37.68(1.78)$ & $31.52(2.16)$ \\
\hline
\end{tabular}

${ }^{a}$ Value in parentheses indicates the sample standard deviation where $n=6$.

sion data resulted in no significant correlation $(P=0.05)$ between the model parameters and the experimental variables.

4. The Cooper-Eaton model indicates that the primary mechanism in the densification of RDF derived biomass is attributed to particle rearrangement, with some secondary influence from plastic deformation or particle fragmentation.

5. Peleg and Moreyra's model, fit to the data, estimated the asymptotic modulus $\left(E_{\mathrm{a}}\right)$ for each sample and indicated that pellets formed from the RDF material had a higher $E_{\mathrm{a}}$ value than the biodegradable pellets; RDF-derived materials are determined to have comparable $E_{\mathrm{a}}$ values to literature values for other biological residues.

\section{Acknowledgements}

This research has been in collaboration with the Edmonton Waste Management Centre. Significant funding was provided by BioFuelNet Canada under the waste as feedstocks project.

\section{Nomenclature}

ASABE

American Society of Agricultural and Biological Engineers

BFN BioFuelNet

EWMC Edmonton Waste Management Centre

MSW Municipal Solid Waste

PAR Percent Average Relaxation

RDF Refuse Derived Fuel

\begin{tabular}{|c|c|}
\hline SPU & Single Pelleting Unit \\
\hline$A_{\mathrm{a}}$ & cross-sectional area $\left(\mathrm{m}^{2}\right)$ \\
\hline$a_{1}$ & Kawakita-Lüdde model constant \\
\hline$a_{2}$ & Cooper-Eaton model constant \\
\hline$a_{3}$ & Cooper-Eaton model constant \\
\hline$b_{1}$ & Kawakita-Lüdde model constant \\
\hline$b$ & Walker model constant \\
\hline$b^{\prime}$ & Jones model constant \\
\hline$C$ & volume ratio \\
\hline$E_{\mathrm{a}}$ & asymptotic modulus, (MPa) \\
\hline$F_{\mathrm{e}}$ & final relaxation force $(\mathrm{kN})$ \\
\hline$F_{0}$ & initial relaxation force $(\mathrm{kN})$ \\
\hline$F(t)$ & relaxation for at time $t(\mathrm{kN})$ \\
\hline$k_{1}$ & Cooper-Eaton model constant \\
\hline$k_{2}$ & Cooper-Eaton model constant \\
\hline$k_{3}$ & Peleg-Moreyra model constant \\
\hline$k_{4}$ & Peleg-Moreyra model constant \\
\hline$m$ & Walker model constant \\
\hline$m^{\prime}$ & Jones model constant \\
\hline$P$ & pressure $(\mathrm{MPa})$ \\
\hline$t$ & time $(\mathrm{s})$ \\
\hline$T$ & temperature $(\mathrm{K})$ \\
\hline$V$ & volume of compacted material $\left(\mathrm{m}^{3}\right)$ \\
\hline$V_{0}$ & initial volume at zero pressure $\left(\mathrm{m}^{3}\right)$ \\
\hline$V_{\mathrm{s}}$ & void-free solid volume $\left(\mathrm{m}^{3}\right)$ \\
\hline$\varepsilon$ & strain \\
\hline$\rho$ & compact density $\left(\mathrm{kg} / \mathrm{m}^{3}\right)$ \\
\hline
\end{tabular}




\section{Refertences}

Adapa P., Tabil L. Schoenau G., Compression characteristics of non-treated and steam-exploded barley, canola, oat, and wheat straw grinds. Applied Engineering in Agriculture, 26 (2010) 617-632.

ASABE (American Society of Agricultural and Biological Engineers Standards), ASAE S358.3 Moisture measurement—forages, ASABE, St. Joseph, Michigan, 2008.

BioFuelNet (BioFuelNet Canada), 2015, What are biofuels? $<$ http://www.biofuelnet.ca/wp-content/uploads/2015/01/ Infographics11.png $>$ accessed 15.02.2017.

Cooper A., Eaton L., Compaction behavior of several ceramic powders, Journal of the American Ceramic Society, 45 (1962) 97-101.

EWMC (Edmonton Waste Management Centre), 2015, Wasteto-biofuels and chemicals facility: turning garbage into fuel $<$ www.edmonton.ca/programs_services/garbage_waste/ biofuels-facility.aspx $>$ accessed 15.02.2017.

Jones W.D., Fundamental principles of powder metallurgy, Edward Arnold Publishers Ltd., London, 1960, pp. 242370.

Kawakita K, Lüdde K., Some considerations on powder compression equations, Powder Technology, 4(1971) 61-68.

Mani S., Tabil L., Sokhansanj S., An overview of compaction of biomass grinds, Powder Handling \& Processing, 15 (2003) $160-168$.

Mani S., Tabil L., Sokhansanj S., Effects of compressive force, particle size, and moisture content on mechanical proper- ties of biomass pellets from grasses, Biomass and Bioenergy, 30 (2006) 648-654.

Mor S., Ravindra K., Visscher A. De, Dahiya R., Chandra A., Municipal solid waste characterization and its assessment for potential methane generation: A case study, Science of the Total Environment, 371 (2006) 1-10.

Moreyra R., Peleg M., Compressive deformation patterns of selected food powders, Journal of Food Science, 45 (1980) $866-868$.

Payne J.D., Improving quality of pellet feeds, Milling Feed and Fertilizer, 161 (1978) 3441.

Shaw M, Feedstock and process variables influencing biomass densification, M.Sc. Thesis, 2008.

Sokhansanj S., Mani S., Bi X., Zaini P., Tabil L., Binderless pelletization of biomass, Presented at the ASAE Annual International Meeting, July 17-20, 2005, Tampa, Florida. ASAE Paper No. 056061. ASAE, 2950 Niles Road, St. Joseph, MI 49085-9659 USA.

Talebi S., Tabil L., Opoku A., Shaw M., Compression and relaxation properties of timothy hay, International Journal of Agricultural and Biological Engineering, 4 (2011) 69-78.

Walker E., The properties of powders-Part VI: The compressibility of powders, Transactions of the Faraday Society, 19 (1923) 73-82.

Yaman S., Şahan M., Haykiri-açma H., Şeşen K., Küçükbayrak S., Production of fuel briquettes from olive refuse and paper mill waste, Fuel Processing Technology, 68 (2000) $23-31$. 


\section{Author's short biography}
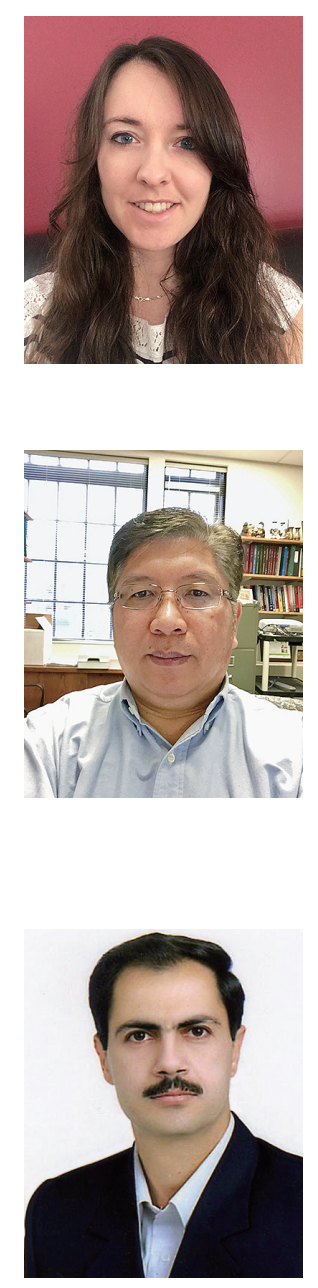

\section{Charley Sprenger}

Charley Sprenger is a MSc candidate in the Department of Chemical and Biological Engineering, University of Saskatchewan. Her thesis research is in the area of preprocessing of municipal solid waste for biofuels applications.

\section{Lope G. Tabil}

Lope G. Tabil, is a Professor of Biological Engineering in the Department of Chemical and Biological Engineering, University of Saskatchewan. The areas of research in which he works and maintains interest include bioprocess engineering, value-added engineering, biomass energy and postharvest handling of crops. He has also conducted research and development projects related to value-added processing of agricultural products including storage, drying and cooling, and physical properties of agricultural and biological materials.

\section{Majid Soleimani}

Majid Soleimani is a PDF Research Associate at the Department of Chemical and Biological Engineering, University of Saskatchewan. His research interests are in bioproducts, biofuels, and biomaterials. He did his $\mathrm{PhD}$ in Industrial Biotechnology-Bioprocess Engineering. The title of his thesis was "Xylitol production in free- and immobilized-cell bioconversions from lignocellulosic biomass". The major focus of the thesis was on the kinetic study of xylitol production in homogeneous and heterogeneous bioreactors. In the last few years, he has been working on biomass densification (granulation and pelletization) and some thermochemical processes such as torrefaction for solid biofuel applications. Also, he has been involved in a few projects on biocomposites, including fully- and partially-degradable composites for structural applications or as cell support in biocatalysis. 